\title{
Seroprevalence of Toxoplasmosis Detected by RDT in Residents near the DMZ (demilitarized zone) of Cheorwon-gun, Gangwon-do, Korea
}

\author{
Yeong Hoon Kim¹, Jihoo Lee², Young-Eun Kim², Seongkyu Ahn³, Tong-Soo Kim³, Sung-Jong Hong ${ }^{4}$, \\ Chom-Kyu Chong ${ }^{2}$, Hye-Jin Ahn ${ }^{5}$, Ho-Woo Nam ${ }^{5, *}$ \\ ${ }^{1}$ Department of Ophthalmology, College of Medicine, Catholic University of Korea, Seoul 06591, Korea; ' Genbody Inc., Cheonan 31116, Korea; \\ ${ }^{3}$ Department of Parasitology and Tropical Medicine and Inha Research Institute for Medical Sciences, Inha University School of Medicine, Incheon \\ 22333, Korea; ${ }^{4}$ Department of Medical Environmental Biology, Chung-Ang University College of Medicine, Seoul 06974, Korea; ${ }^{5}$ Department of \\ Parasitology, College of Medicine, Catholic University of Korea, Seoul 06591, Korea
}

\begin{abstract}
Seroprevalence of Toxoplasma gondii infection among the residents of Cheorwon-gun, Gangwon-do, Korea, which partly includes the demilitarized zone (DMZ), were surveyed for 4 years and evaluated by RDT using recombinant fragment of major surface antigen (SAG1A). Sera from 1336, 583, 526, and 583 adult residents were collected on a yearly basis from 2010 to 2013 , respectively. The total positive seroprevalence was $19.3,21.9,23.4$, and $26.8 \%$ from 2010 to 2013, respectively. The positive seroprevalence in men (23.6, 27.5, 29.5, 34.6\%) was far higher than women (14.1, 18.3, $19.4,21.4 \%$ ), from 2010 to 2013, respectively. This high seroprevalence of toxoplasmosis in Cheorwon-gun may have been influenced in part by its geographical locality of the area as it includes the DMZ, where civilian access is strictly limited, thus creating a relatively isolated area that is a well-preserved habitat. Further research is necessary to study the epidemiology of toxoplasmosis in this area.
\end{abstract}

Key words: Toxoplasma gondii, seroprevalence, Cheorwon-gun, DMZ, RDT

\section{INTRODUCTION}

Toxoplasma gondii, an apicomplexan zoonotic protozoa, is one of the most prevalent and successful parasites worldwide. Felids are its definitive host, and all other warm blooded animals including humans are its intermediate hosts. Toxoplasmosis is acquired either through the ingestion of tissue cysts from undercooked meat, or consumption of food or water contaminated with oocysts. Placental transmission of T. gondii may cause congenital toxoplasmosis [1-3], which may result in stillbirth or abortion in addition to serious damages to the fetus such as severe neurological disorders after delivery $[4,5]$. Although clinical symptoms are rare following exposure, the infections can transform into a chronic form, sometimes causing toxoplasmic lymphadenitis, meningoencephalitis or ocu-

\footnotetext{
- Received 8 June 2017, revised 17 July 2017, accepted 19 July 2017.

*Corresponding author (howoo@catholic.ac.kr)

(C) 2017, Korean Society for Parasitology and Tropical Medicine

This is an Open Access article distributed under the terms of the Creative Commons Attribution Non-Commercial License (http://creativecommons.org/licenses/by-nc/4.0) which permits unrestricted non-commercial use, distribution, and reproduction in any medium, provided the original work is properly cited.
}

lar toxoplasmosis in immune compromised patients [6-9].

Many surveys on toxoplasmosis have been performed in Korea [10-15], which showed that the seroprevalence was 1.9 to $5.8 \%$ with the ILA test [10] and up to $7.7 \%$ with the more sensitive ELISA [11]. But these values were still significantly lower than those of other countries with high positive seroprevalences, which ranged from 30 to $70 \%$ [3]. However, recent surveys have demonstrated an increasing positive seroprevalence rate ranging from 12.9 to $17.0 \%$ in certain parts of Korea [10,12-14].

Rapid diagnostic test (RDT), the current universal trend for diagnosis is gradually replacing ELISA as a tool for the diagnosis of toxoplasmosis, because it is a time-consuming procedure and requires a skilled technician.

Korea has an almost 100\% full health-coverage of its population, yet its seroprevalence of toxoplasmosis in certain areas is high or increasing recently, which suggests some changes in the toxoplasmic environment [14]. The current study presents results of a 4 year-survey on the seroprevalence of toxoplasmosis by RDT among the residents of Cheorwon-gun, Gangwondo, Korea, which partly includes the demilitarized zone (DMZ), 


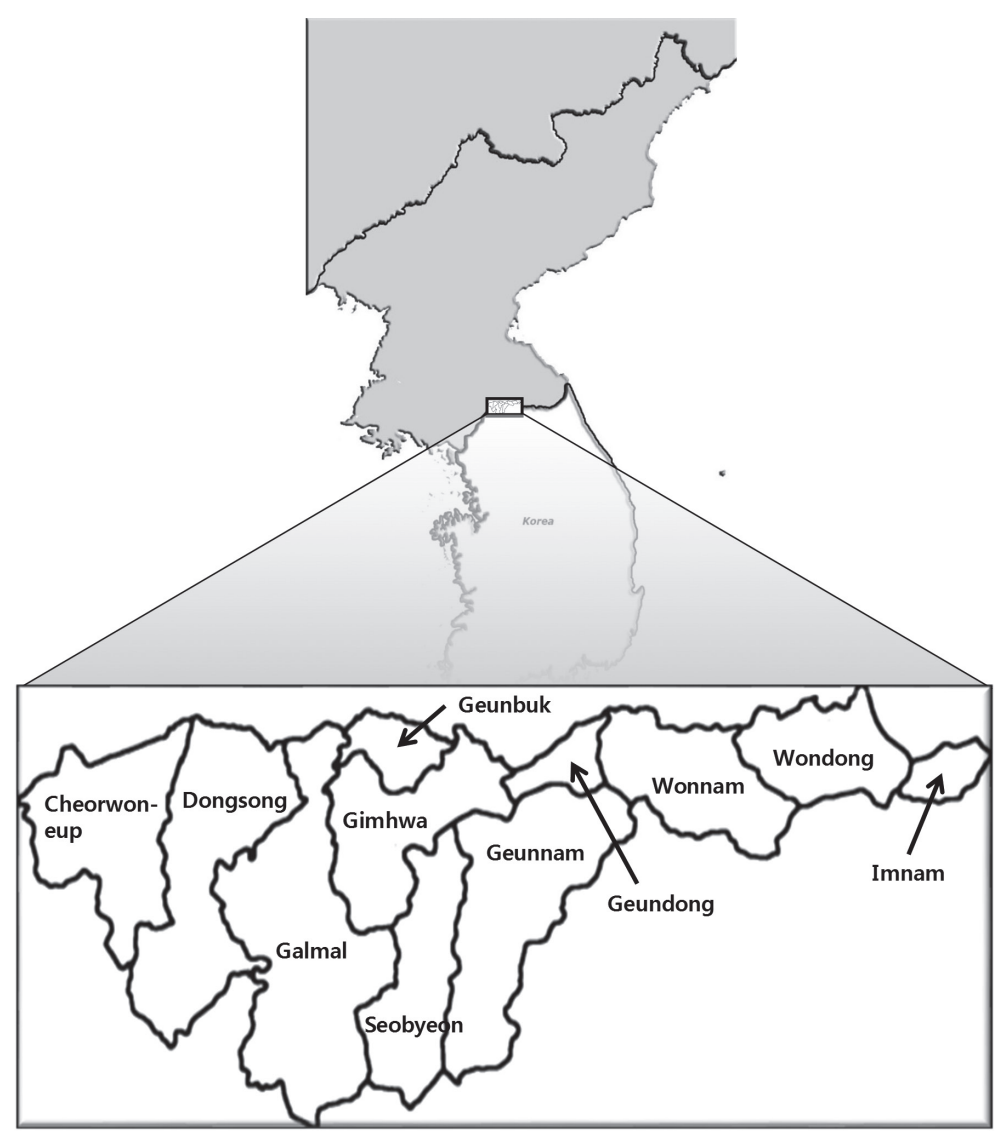

Fig. 1. The surveyed area (Cheorwon-gun, Gangwon-do, Korea, which partly includes the DMZ (demilitarized zone). The 4 rightmost districts (Geundong, Wonnam, Wondong, and Imnam) are strictly off-limits to civilians.

an area where civilian access is strictly regulated. We discuss the general trend of toxoplasmosis in the area, and try to postulate the significance of its high prevalence and probable cause.

\section{MATERIALS AND METHODS}

\section{Ethics statement}

This study was performed under the regulation of the IRB Committee of Chung-Ang University (no. 2010-06-03) and the IRB Committee of Inha University (no. 2012-28 and 2013008). This research adhered to the tenets of the Declaration of Helsinki. All participants provided written informed consent, and no minors were involved in the study.

All procedures and handling of mice were conducted under an approved protocol by the Institutional Animal Care and Use Committee (IACUC) at the School of Medicine, Catholic University of Korea (no. CUMC-2015-0042-02, 2015-2017), which adhered to the regulations set under the Korean $\mathrm{Na}$ -
Table 1. Seroprevalence of $T$. gondii by RDT in Cheorwon-gun (Gangwon-do, Korea) residents according to gender

\begin{tabular}{lrrc}
\hline Year & Total & Male & Female \\
\hline 2010 & $258 / 1,336(19.3)^{a}$ & $172 / 728(23.6)$ & $86 / 608(14.1)$ \\
2011 & $128 / 583(21.9)$ & $64 / 233(27.5)$ & $64 / 350(18.3)$ \\
2012 & $123 / 526(23.4)$ & $61 / 207(29.5)$ & $62 / 319(19.4)$ \\
2013 & $156 / 583(26.8)$ & $82 / 237(34.6)$ & $74 / 346(21.4)$ \\
\hline
\end{tabular}

aPercentage of positive cases.

tional Animal Protection Act.

\section{Serum collection}

Sera from 1336, 583, 526, and 583 adult residents in Cheorwon-gun, Gangwon-do, Korea (Fig. 1) were collected on a yearly basis from 2010 to 2013 (Table 1).

\section{Rapid diagnostic test (RDT)}

IgG/IgM RDT mounted with recombinant fragment of major surface antigen (SAG1A), GST-linker-SAG1A [12,16], were 


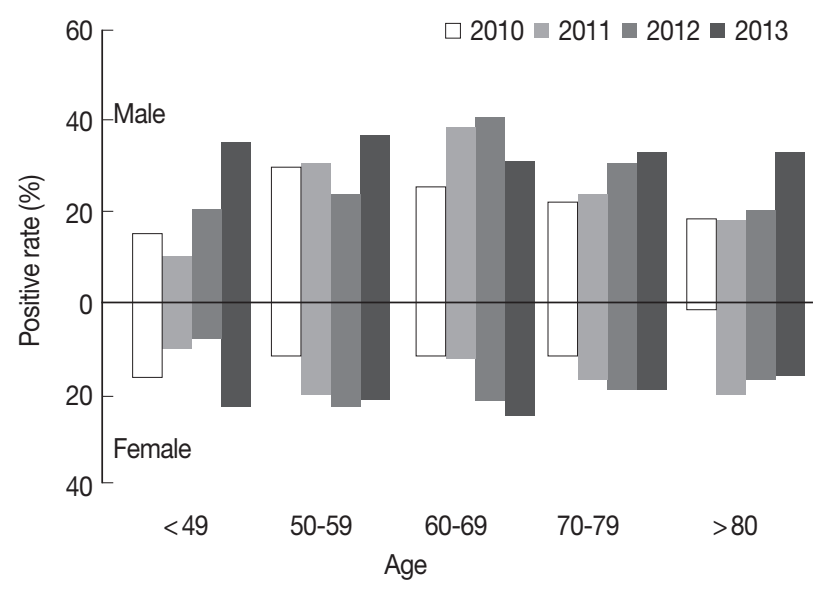

Fig. 2. General trends of positive seroprevalence of toxoplasmosis according to gender and age in the surveyed area.

applied to the sera mentioned above.

Briefly, $10 \mu$ of serum was applied to the RDT sample hole and eluted with RDT buffer a few seconds later. Reacting bands were read after 15-20 min and its density was determined arbitrarily as $0,+,++$, and +++ . Definite reactivity was determined as ++ (mid), while weaker and stronger reactivity compared to it was determined as + (weak) and +++ (strong). The final results were agreed upon by the 3 investigators.

\section{RESULTS}

The positive seroprevalence of the residents in Cheorwongun was high from the beginning of the survey in 2010 at $19.3 \%$ (258/1336). The posivitive seroprevalence was maintained at high rates in subsequent years, and simultaneously showed a gradual increase, to $21.9 \%$ (128/583), 23.4\% (123/526), and 26.8\% (156/583) in 2011, 2012, and 2013, respectively (Table 1; Fig. 2).

According to gender, the positive rate of males was always higher than that of females, maintaining roughly a 1.5 ratio throughout the survey period. The positive rate of both genders showed a gradual increase in subsequent years.

In regard to age, positive rates increased gradually in most age groups, regardless of gender. The seroprevalence actually decreased gradually in the $<49$ years old female group from 2010 to 2012, but surged back in 2013, exceeding the seroprevalence seen initially in 2010.

The $>80$ years old female group showed a fairly low seroprevalence in 2010, but a major surge was observed the next year in 2011, after which a similar gradual decrease that was

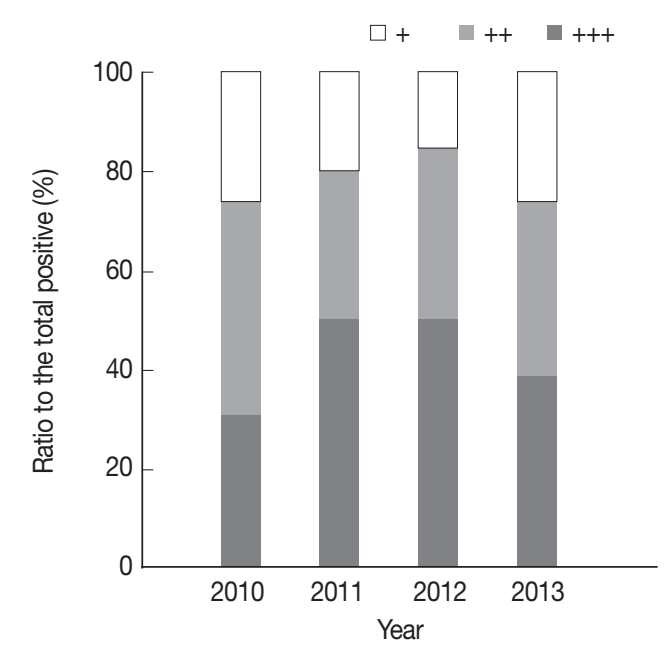

Fig. 3. Changing patterns of RDT reactivity of toxoplasmosis in seropositive cases.

also present in the $<49$ years old female group was observed.

When comparing the age groups according to gender, the positive rate of men was always higher than that of women in the same age group, as noted above. Nevertheless, positive seroprevalence showed a steady increasing trend in both genders (Fig. 2).

RDT reactivity changes were also observed in seropositive cases during the survey period. The ratio of the mid-reactivity group was relatively constant. However, the strong-reactivity group showed a gradual decrease in its ratio, from 2010 to 2012. It surged back to the 2010 ratio in 2013. The weak-reactivity group showed a mirror-shaped change to that of the strong-reactivity group (Fig. 3).

\section{DISCUSSION}

Since Soh et al. [17] first reported the seropositive rate of $5.6 \%$ in 373 Koreans by skin test using toxoplasmin in 1960, several serological methods, such as indirect fluorescent antibody test (IFAT), indirect latex agglutination test (ILA), and ELISA, have been developed for detection of T. gondii infection. However, most of these methods need whole cell lysates of $T$. gondii as an antigen, which is expensive and time-consuming to prepare. We developed a detection method in the form of rapid diagnostic test (RDT) using recombinant proteins as antigens [16] to overcome these disadvantages.

The seroprevalence of $T$. gondii in Korea has remained relatively constant since 1960 . However, a major surging increase can be observed since 2010 among residents of Cheorwon- 
gun. The explosive increase in seroprevalence may have been caused by several factors that may reflect environmental and socioeconomic changes undergoing in Korea. Our study has been performed around the border of Korea, one of the most naturally preserved areas in the world [18]. Not surprisingly, a relatively high population of local fauna would result in a high seroprevalence of intermediate hosts for T. gondii [19]. Sometimes local wild animals are captured by a snare to be consumed among family members and relatives.

Meat consumption, both domestic and imported, has increased dramatically in Korea. Combined with the organic fervor seen nowadays, domestic free-range animals are in high demand, which could be another potential route for toxoplasma infection $[20,21]$. Another source of infection, albeit minor, may be migratory birds $[22,23]$. As mentioned above, Cheorwon-gun includes the DMZ, where civilian access is limited, thus creating a relatively isolated area that is a well-preserved, world-renown temperate natural habitat. This area provides an important shelter for these birds. During the avian influenza crisis in recent years, a high number of migratory birds have been positively identified with the virus, these birds may transmit toxoplasmosis from high endemic regions [24].

The positive seroprevalence of men was always higher than that of women, maintaining roughly a 1.5 -fold higher ratio throughout the survey period. Some Koreans, mostly men, still have the misbelief that the raw viscera of animals have special nutrients good for their stamina, so they eat them raw. This may in part explain the higher toxoplasma seroprevalence of men observed in our study, besides being more socioeconomically active.

In regard to age, positive rates increased gradually in all age groups, regardless of gender. However, the seroprevalence actually decreased gradually in the $<49$ years old female group from 2010 to 2012, but surged back in 2013, exceeding the seroprevalence seen initially in 2010. This group may have experienced a population shift as younger women moved away from this area, while new infections developed among the remaining population. The gradual decrease that was present in the $<49$ years old female group was also observed in the $>80$ years old female group. Population decrease due to death caused by advanced age may have been a contributing factor.

Our previous study has determined the overall specificity and sensitivity of the RDT to be $100 \%$ and $97.1 \%$, respectively [16]. RDT uses rSAG1A-GRA2 antigen [12,16]. A chronic infection history implies abundant antibodies against various antigens such as SAGs, GRAs, and MICs, which could be detected by the ELISA, whereas RDT would be limited in this respect, as only 2 antigens are detected.

RDT reactivity changes were also observed among seropositive cases during the survey period. The ratio of the mid-reactivity group was relatively constant, but the strong-reactivity group showed a gradual decrease in its ratio, from 2010 to 2012, which surged back to the 2010 ratio in 2013. The weakreactivity group showed a mirror-shaped change to that of the strong-reactivity group. If we assume strong reactivity as being responsible for active or new infection, it may be implied that the incidence of new cases of toxoplasmosis was on the decline, but then recurred back in force after 2013. Subsequent studies may shed light on the issue.

Toxoplasmosis is prevalent throughout the world but clinical manifestations are rare, so it is mainly neglected in major health policies. Korea is on the verge of becoming an advanced country with an almost $100 \%$ full health-coverage of its population, yet its seroprevalence of toxoplasmosis in certain areas is increasing rapidly. A major surge in seroprevalence, coupled with a change in disease characteristics at any point in the future may cause a major health threat. It is necessary to find both symptomatic and asymptomatic patients and confirm their risk factors. The current study presents a general trend of toxoplasmosis in the Cheorwon area, and provides basic data which could be helpful for establishing plans to control the potential complications of Toxoplasma infection, namely lympadenitis, retinochoroiditis, and encephalitis [25-27].

In conclusion, we recommend continuous periodic surveys to determine the infection status, including new infections, of T. gondii. Indeed, the problems may not be limited to this relatively isolated area, so the postulated causes in this study may be applied to a full-scale national survey to screen the national Toxoplasma seroprevalence.

\section{ACKNOWLEDGMENT}

This study was supported by a research grant from the Korean Association of Health Promotion (no. 2015-01), Seoul, Korea.

\section{CONFLICT OF INTEREST}

We have no conflict of interest related to this study. 


\section{REFERENCES}

1. Black MW, Boothroyd JC. Lytic cycle of Toxoplasma gondii. Microbiol Mol Biol Rev 2000; 64: 607-623.

2. Furtado JM, Smith JR, Belfort R Jr, Gattey D, Winthrop KL. Toxoplasmosis: a global threat. J Glob Infect Dis 2011; 3: 281-284.

3. Tenter AM, Heckeroth AR, Weiss LM. Toxoplasma gondii: from animals to humans. Int J Parasitol 2000; 30: 1217-1258.

4. Montoya JG, Remington JS. Management of Toxoplasma gondii infection during pregnancy. Clin Infect Dis 2008; 47: 554-566.

5. Song KJ, Shin JC, Shin HJ, Nam HW. Seroprevalence of toxoplasmosis in Korean pregnant women. Korean J Parasitol 2005; 43: 69-71.

6. Weiss LM, Dubey JP. Toxoplasmosis: a history of clinical observations. Int J Parasitol 2009; 39: 895-901.

7. Choi WY, Nam HW, Kwak NH, Huh W, Kim YR, Kang MW, Cho SY, Dubey JP. Foodborne outbreaks of human toxoplasmosis. J Infect Dis 1997; 175: 1280-1282.

8. Kim MH, Choi YK, Park YK, Nam HW. A toxoplasmic uveitis case of a 60-year-old male in Korea. Korean J Parasitol 2000; 38 : 29-31.

9. Park YH, Han JH, Nam HW. Clinical features of ocular toxoplasmosis in Korean patients. Korean J Parasitol 2011; 49: 167-171.

10. Choi WY, Nam HW, Youn JH, Kim WS, Kim WK. Toxoplasma antibody titers by indirect latex agglutination test in patients of Kangnam St. Mary's Hospital and Cheju Medical Center. Korean J Parasitol 1989; 27: 171-175.

11. Choi WY, Nam HW, Youn JH, Kim DJ, Kong Y, Kang SY, Cho SY. Detection of antibodies in serum and cerebrospinal fluid to Toxoplasma gondii by indirect latex agglutination test and enzyme-linked immunosorbent assay. Korean J Parasitol 1992; 30: 83-90.

12. Hong SJ, Chong CK, Lee K, Kim TS, Hong YP, Ahn HJ, Kim HY, Ko AR, Kim YJ, Nam HW. Maintained seroprevalence of toxoplasmosis among the residents of Jeju island, Korea. Korean J Parasitol 2011; 49: 309-311.

13. Yang HJ, Jin KN, Park YK, Hong SC, Bae JM, Lee SH, Choi HS, Hwang HS, Chung YB, Lee NS, Nam HW. Seroprevalence of toxoplasmosis in the residents of Cheju island, Korea. Korean J Parasitol 2000; 38: 91-93.

14. Ahn HJ, Cho PY, Ahn SK, Kim TS, Chong CK, Hong SJ, Cha SH, Nam HW. Seroprevalence of toxoplasmosis in the residents of Cheorwon-gun, Gangwon-do, Korea. Korean J Parasitol 2012; 50: 225-227.

15. Yang Z, Cho PY, Ahn SK, Ahn HJ, Kim TS, Chong CK, Hong SJ, Cha SH, Nam HW. A surge in the seroprevalence of toxoplasmosis among the residents of islands in Gangwha-gun, Incheon, Korea. Korean J Parasitol 2012; 50: 191-197.
16. Song KJ, Yang Z, Chong CK, Kim JS, Lee KC, Kim TS, Nam HW. A rapid diagnostic test for toxoplasmosis using recombinant antigenic N-terminal half of SAG1 linked with intrinsically unstructured domain of gra2 protein. Korean J Parasitol 2013; 51: 503-510.

17. Soh CT, Lee SJ, Ahn YK. Latent infection by Toxoplasma gondii in Korea. Yonsei Med J 1960; 1: 52-54.

18. Kim KC. Preserving biodiversity in Korea's demilitarized zone. Science 1997; 278: 242-243.

19. Kim DG, Park JH, Kim JL, Jung BK, Jeon SJ, Lim H, Lee MY, Shin EH, Klein TA, Kim HC, Chong ST, Song JW, Baek LJ, Chai JY. Intestinal nematodes from small mammals captured near the demilitarized zone, Gyeonggi province, Republic of Korea. Korean J Parasitol 2015; 53: 135-139.

20. Dubey JP, Hill DE, Rozeboom DW, Rajendran C, Choudhary S, Ferreira LR, Kwok OC, Su C. High prevalence and genotypes of Toxoplasma gondii isolated from organic pigs in northern USA. Vet Parasitol 2012; 188: 14-18.

21. Tilahun G, Tiao N, Ferreira LR, Choudhary S, Oliveira S, Verma SK, Kwok OC, Molla B, Saville WJ, Medhin G, Kassa T, Aleme H, Gebreyes WA, Su C, Dubey JP. Prevalence of Toxoplasma gondii from free-range chickens (Gallus domesticus) from Addis Ababa, Ethiopia. J Parasitol 2013; 99: 740-741.

22. Sandstrom CA, Buma AG, Hoye BJ, Prop J, van der Jeugd H, Voslamber B, Madsen J, Loonen MJ. Latitudinal variability in the seroprevalence of antibodies against Toxoplasma gondii in nonmigrant and Arctic migratory geese. Vet Parasitol 2013; 194: 9-15.

23. Verma SK, Calero-Bernal R, Cerqueira-Cezar CK, Kwok OC, Dudley M, Jiang T, Su C, Hill D, Dubey JP. Toxoplasmosis in geese and detection of two new atypical Toxoplasma gondii strains from naturally infected Canada geese (Branta canadensis). Parasitol Res 2016; 115: 1767-1772.

24. Hill NJ, Ma EJ, Meixell BW, Lindberg MS, Boyce WM, Runstadler JA. Transmission of influenza reflects seasonality of wild birds across the annual cycle. Ecol Lett 2016; 19: 915-925.

25. Katwere M, Kambugu A, Piloya T, Wong M, Hendel-Paterson B, Sande MA, Ronald A, Katabira E, Were EM, Menten J, Colebunders R. Clinical presentation and aetiologies of acute or complicated headache among HIV-seropositive patients in a Ugandan clinic. J Int AIDS Soc 2009; 12: 21.

26. Leligdowicz A, Katwere M, Piloya T, Ronald A, Kambugu A, Katabira E. Challenges in diagnosis, treatment and follow-up of patients presenting with central nervous system infections in a resource-limited setting. Mcgill J Med 2006; 9: 39-48.

27. Luft BJ, Chua A. Central nervous system toxoplasmosis in HIV pathogenesis, diagnosis, and therapy. Curr Infect Dis Rep 2000; 2: $358-362$. 
